\title{
1 Food insecurity, macronutrient intake and patterns of eating in a sample of UK adults
}

3

\section{Authors:}

Jackie Shinwell $^{1}$, Melissa Bateson ${ }^{2}$, Daniel Nettle ${ }^{1}$, Gillian V. Pepper ${ }^{3}$

1. Population Health Sciences Institute, Newcastle University, Newcastle, UK

2. Biosciences Institute, Newcastle University, Newcastle, UK

3. Department of Psychology, Northumbria University, Newcastle, UK

Corresponding author contact details: Dr Gillian Pepper, Northumberland Building, Northumbria University, Newcastle upon Tyne, NE1 8ST, UK, gillian.pepper@northumbria.ac.uk, +0044 (0)191 2273882.

Short title: Food insecurity and patterns of eating

\section{Financial support}

This project has received funding from the European Research Council (ERC) under the European Union's Horizon 2020 research and innovation programme (grant agreement No AdG 666669, COMSTAR).

\section{Conflicts of Interest}

The authors declare that they have no conflicts of interest.

\section{Authorship using CRediT taxonomy:}

Shinwell, J: Conceptualization, Data curation, Formal Analysis, Investigation, Visualization, Project administration, Methodology, Writing - original draft, Writing - review \& editing

Bateson, M: Conceptualization, Methodology, Writing - review \& editing

Nettle, D: Conceptualization, Resources, Formal Analysis, Supervision, Funding acquisition,

Visualization, Methodology, Project administration, Writing - review \& editing

Pepper, G, V.: Conceptualization, Supervision, Investigation, Visualization, Methodology, Project administration, Writing - review \& editing

Ethical Standards Disclosure: This study was conducted according to the guidelines laid down in the Declaration of Helsinki and all procedures involving research study participants were approved by the Newcastle University Faculty of Medical Sciences Ethics Committee (ref: 24577). Written informed consent was obtained from all subjects. 


\section{Abstract}

31 How do the dietary intake patterns of people exposed to food insecurity differ from those of

32 people who are food secure? A recent study of a US sample found that food insecurity was

33 associated with greater reliance on carbohydrate, a lower diversity of food, and more variable

34 time gaps between eating. We examined whether these features were also present in a sample

35 of UK adults. From a low-income population, we recruited matched groups of participants

36 who were classified as food insecure $(n=196)$ or food secure $(n=198)$ according to a

37 standard questionnaire measure. We collected up to five twenty-four-hour dietary recalls

38 from each participant. Results were strikingly like those from the US study. Food insecure respondents consumed relatively more carbohydrate and less protein; had fewer distinct foods

40 per meal; and had more variable time gaps between meals. Food insecure participants did not

41 have significantly higher body mass indices in this study. Food insecurity as measured by

42 questionnaire appears to relate to a repeatable set of changes to dietary intake across

43 populations. 


\section{Introduction}

How do the diets of people experiencing food insecurity differ from people who are food secure? In this paper, we address this question using four days of 24-hour food recall data from a sample of British adults designed to contain equal numbers of food secure and food insecure individuals. Food insecurity (FI) is defined as the 'the inability to acquire or consume an adequate quality or sufficient quantity of food in socially acceptable ways, or the uncertainty that one will be able to do so' (Dowler \& O'Connor, 2012, p. 1). FI is associated with poorer health, higher mortality, and, in the case of women, a greater risk of overweight or obesity, even after adjusting for socioeconomic position (Kowaleski-Jones et al., 2018; Laraia, 2012; Larson \& Story, 2011; Nettle et al., 2017; Pan et al., 2012; Townsend et al., 2001; Vozoris \& Tarasuk, 2003). Some of these health consequences may be due to different patterns of dietary intake in people experiencing FI, compared with people who are not (Kendall et al., 1996; Nettle \& Bateson, 2019; Zizza et al., 2008). But how exactly do patterns of dietary intake differ with FI? The questionnaires used to assess FI do not answer this question in detail, since they consist of general statements such as "we couldn't afford to eat balanced meals". The response to this question carries no information about exactly how the meals were unbalanced. The question can therefore only be addressed with datasets where the same individuals complete FI questionnaires, and also provide detailed dietary recall information separately.

In a recent study, Nettle \& Bateson, (2019) used two days of nutritional intake data from the US National Health and Nutrition Examination Survey (NHANES, 2013-4) to quantify the differences in dietary intake patterns between women classified as food insecure and food secure. They found several clear differences, which we review below, some of which have also been observed in other studies. However, the same analyses have not yet been replicated in other samples, so the generality of the observed patterns is unknown. Here, we seek to replicate the analyses of Nettle \& Bateson (2019) in an independent sample from a different country, the UK. Our goal is to answer the questions: are the ways that food-insecure people eat differently, as documented in Nettle and Bateson (2019), specific to the US population they studied, or can they be independently observed in a sample from the UK population, 6-7 years later?

Nettle \& Bateson (2019) found no difference in total energy intake between food secure and food insecure women but significant associations between FI status and macronutrient intake; the number of consumption events (CEs); and the temporal patterning of CEs. Food insecure 
women ate more carbohydrate but less protein and fibre. They had fewer CEs each day with fewer distinct foods and less variability of foods at each CE. Their first CE was also later in the day and they had greater variability in time gaps between CEs. Food insecure women also had a higher BMI. Similarly, prior research has found no difference in total energy intake between food secure and food insecure adults (Basiotis \& Lino, 2002; Bocquier et al., 2015; Dixon et al., 2001; Leung et al., 2014; Zizza et al., 2008), but that FI was associated with eating fewer but larger meals (Zizza et al., 2008) and a higher BMI in women (Basiotis \& Lino, 2002; Kowaleski-Jones et al., 2018; Larson \& Story, 2011; Nettle et al., 2017; Pan et al., 2012; Townsend et al., 2001). Nettle \& Bateson (2019) further found that variability in eating patterns, the gap between CEs, the lack of variety of foods consumed at each CE, and low intake of fibre accounted statistically for $14.5 \%$ of the association between FI and BMI.

Several studies have found that macronutrient and energy intake are important factors in regulating weight (Labayen et al., 2014; Martinez, 2000; Nelson \& Tucker, 1996; Sarebanhassanabadi et al., 2020). Temporal variability in eating patterns, including for example, skipping breakfast and eating late at night are also associated with a greater risk of obesity/overweight (Howarth et al., 2007; Murtaugh et al., 2007; Nettle \& Bateson, 2019; Saneei et al., 2016; St-Onge et al., 2017). Moreover, randomised trials showing that making the timing of food intake more variable changes the thermic effect of food, in ways that, if sustained over the long term, would lead to weight gain (Alhussain et al., 2016; Farshchi et al., 2004). Research in animal models shows that experimentally introducing variable time gaps between CEs can lead to mass gain, even without any simultaneous increase in total energy intake (Bateson et al., 2021; Bednekoff \& Krebs, 1995; Cuthill et al., 2000). Establishing whether macronutrient and energy intake and variability in time gaps between CEs differ by food insecurity status could help us to understand why food insecure women are at greater risk of obesity.

Here, we seek to replicate and extend the analysis of the NHANES 2013-14 dataset undertaken by Nettle \& Bateson (2019), but using a UK sample, with four days of nutritional intake data. Our sample, which was generated as a part of an ongoing project, differs from the NHANES in a number of regards. Whereas NHANES is large and nationally representative, ours was smaller (final $n=394$ ), and recruited by purposive sampling. We targeted a population (UK adults on relatively low incomes) likely to contain substantial exposure to food insecurity. From a large number of responses to an initial screening survey, we recruited 
110 a food insecure group, and a food secure group of equal size matched for age and gender.

111 Thus, where the analysis of NHANES relied on controlling statistically for a large number of 112 covariates, our study used a matched group design to make the food secure and food insecure 113 groups roughly comparable in other regards.

114 In their main paper Nettle \& Bateson, (2019) just presented data from women, though they 115 also showed in an appendix that the patterns in men were very similar. As the present UK 116 sample consisted of all genders, we here re-analyse the NHANES 2013-4 data to present all 117 genders combined, for direct comparability.

118 Materials and Methods

119 Data for this study were collected in two phases, as depicted in Figure 1. Phase 1 of the study 120 was a screening exercise used to identify potential participants for phase 2. 


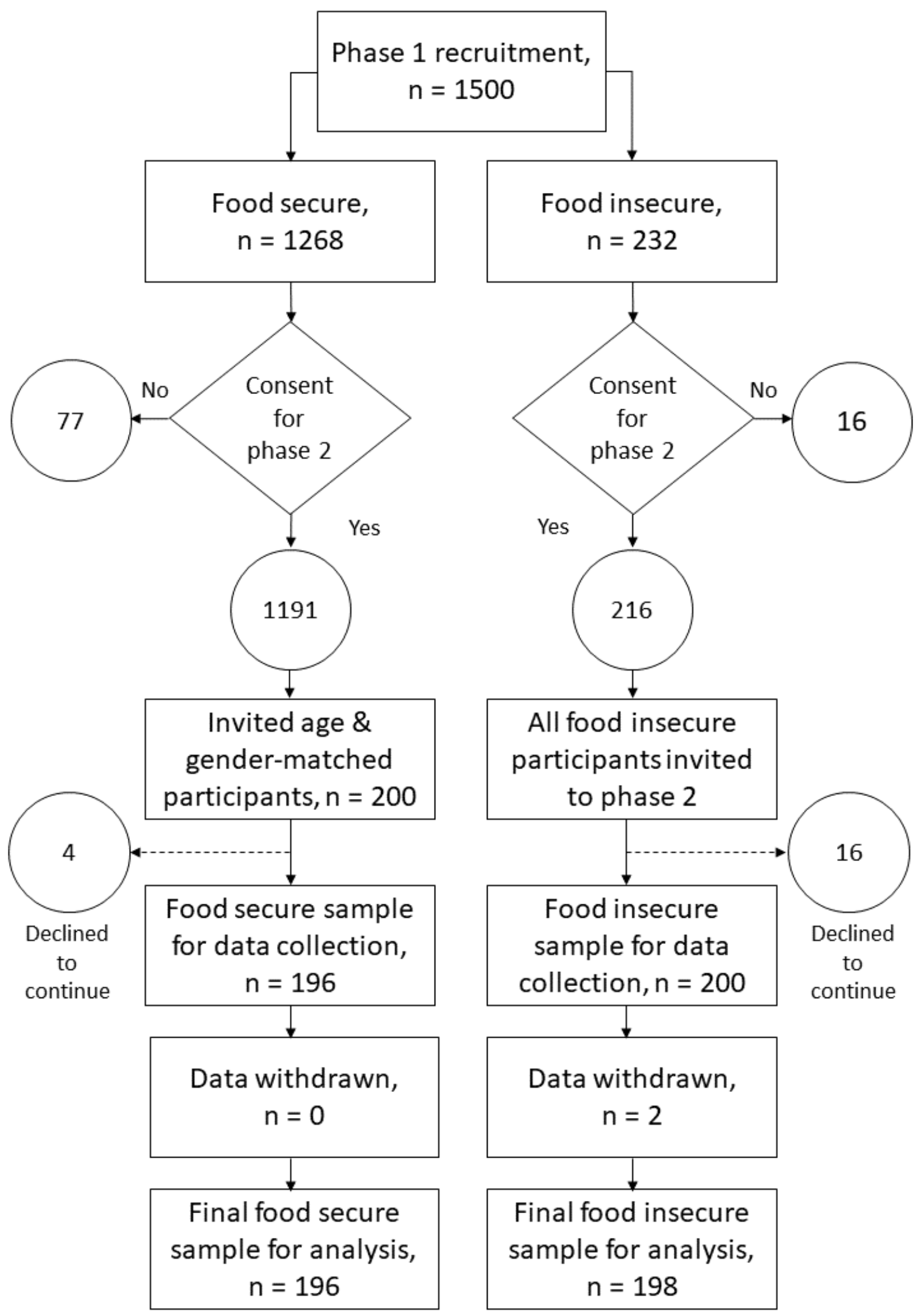

122 Figure 1. A chart depicting the recruitment and sampling (phase 1) and data collection (phase 123 2) stages of the study. 


\section{Phase 1}

\section{Participant recruitment}

Participants were recruited to phase 1 of this study via Prolific. Prolific is an internet based crowd sourcing platform that provides access to a high quality pool of potential research participants (for a review of Prolific, see Peer et al., (2017)). A pre-screening filter was applied to ensure that participants were resident in the UK, were not in full-time education and had a total household income of less than $£ 30,800$ per annum (the median household income in the UK (Office for National Statistics, 2020)). The household income filter was applied in order to identify individuals likely to experience FI, as well as food secure participants of similar socio-economic status. A total of 1500 participants were recruited to phase 1 of the study (male, 598, female, 898, other, 4, see Table S1 of supplementary materials). This sample size was designed to ensure a final food insecure sample of 200 based on the proportion of the UK population estimated to be food insecure at the time of data collection (Loopstra, 2020).

\section{Demographic data}

Demographic data were collected via a Qualtrics questionnaire distributed via Prolific (see Table S1). Measures included: age, gender, self-reported weight and height (from which we calculated body mass index (BMI)), number of people living in the household, whether participants did/paid for most of the food shopping for the household, employment status, and household income.

\section{Food insecurity}

Household FI status was assessed using the Household Food Security Survey Six-Item Short Form module (HFSSM) developed by the US National Centre for Health Statistics (NCHS) (USDA Economic Research Services, 2020). The six-item short form module identifies households which are food insecure and/or have very low food security. It has relatively high specificity compared to the longer, 18 item measure developed by the NCHS (USDA Economic Research Services, 2020).

Data for this study were collected during spring/summer 2020, during which pandemic lockdowns had caused turmoil and disruption to normal routines. The type of food insecurity experience we were interested in was that directly comparable to earlier studies such as Nettle and Bateson (2019), not shorter-term anxieties that might have been provoked by the onset of 
the pandemic. We thus amended the HFSSM questions from their usual 'in the last 12 months' timeframe to 'in the 12-month period prior to the pandemic'.

Responses to questions in the HFSSM were coded in accordance with guidance issued by the USA National Centre for Health Research (USDA Economic Research Services, 2020). In accordance with USDA HFSSM guidance, we dichotomised participants' scores into two groups, food secure/marginal food security (score of 0-1) $(\mathrm{n}=1268)$ and low/very low food security (score of 2-6) $(\mathrm{n}=232)$.

\section{Phase 2}

\section{Participant recruitment}

Data collected in Phase 1 were used to identify participants for phase 2 of the study (see Figure 1). At the end of phase 1, participants were asked to indicate if they could be contacted about participating in phase 2 of the study. A total of 93 participants (77 high or marginal food security status, 16 low or very low food security status) indicated that they did not want to take part in phase 2 , resulting in a potential phase 2 participant pool of 1407 . We invited 216 participants who had low/very low food security status to participate in phase 2 of the study. Sixteen participants declined to take part. The remaining 200 low/very low food security status participants were then matched by age and gender with 200 participants who had high/marginal food security status in phase 1 . Four food secure participants declined to take part. In addition, in accordance with guidance from the developers of Intake 24, the dietary intake collection tool (see below), dietary intake data on two low/very low food secure participants were excluded from the analysis due to incorrect food diary completion. This resulted in a final sample for analysis of 198 low/very low food secure participants and 196 high/marginal food secure participants. For brevity, we henceforth refer to these groups as 'food insecure' and 'food secure' respectively.

\section{Dietary intake}

Dietary intake data were collected using Intake24. Intake24 is an open source, on-line, selfcompletion dietary recall system which was designed to capture food intake in population wide studies. In trials, Intake24 compared favourably with face to face nutritional intake data collection (Bradley et al., 2016; Simpson et al., 2017). Participants were asked to complete four consecutive days of dietary recall. On day 1, participants were sent a link and were asked to record all food and drink and timing of consumption in the previous 24 hours. The following day, a link was sent for day 2 of data collection. This process was repeated until up 
to four days of dietary intake data were recorded. Two participants accidentally completed five days; 370 participants completed four days; 11 participants completed three days; 6 completed two days; and 5 participants, one day.

\section{Mood and sleep}

Data on participants' mood for the previous 24 hours, and how well they slept the night before, were also collected before completing each day's dietary recall. These data are not analysed here but will form the focus of a future study.

\section{Food consumption variables}

In line with the approach adopted by Nettle \& Bateson (Nettle \& Bateson, 2019), we extracted 16 variables of interest from the recall data, organised by $\mathrm{CE}$, with each $\mathrm{CE}$ representing a time when participants consumed an item of food or drink (including water). Details of the variables extracted are presented in Table 1. The variables were of three types: those concerning consumption amounts; those concerning the intra-day patterning of CEs; and those concerning inter-day variation in eating patterns. The consumption amount variables were expressed as daily averages. The relative consumption of different macronutrients was adjusted for total food consumption (i.e., the residual of a regression on amount of macronutrient consumption on total food consumption). In Nettle and Bateson (2019), the inter-day variables were (unsigned) difference scores between the two days, since there were two days of food recall data for each participant in NHANES. For the present UK sample, since there were up to 5 days of recall per participant, the inter-day variables were standard deviations across days rather than difference scores.

\section{Data analysis strategy}

All data analyses were performed in R (R Core Development Team, 2020).

\section{UK data}

Our data analysis closely followed that of Nettle and Bateson (2019). We first used multivariate analyses of variance (MANOVAs) to investigate differences between food secure and food insecure adults for each of the three sets of consumption variables, using FI status as the predictor. The three sets of consumption variables were: consumption amounts (total energy intake and relative carbohydrate, protein, fat, and fibre intake); intraday patterns of eating (time of the first CE, number of CEs, mean number of foods per CE, variability in time gaps between CEs and variability in the amount of energy consumed at each CE), and interday patterns of eating (energy intake, time of the first CE, number of foods, number of CEs and 
219 mean time gaps between CEs). We then followed up these MANOVAs with separate general

220 linear models for each of the sixteen variables individually. We also tested whether FI status

221 predicted BMI.

222 For analysis of our data, we only included gender as a covariate. This was because our food

223 secure and food insecure groups were already matched by age, the recruitment strategy

224 restricted the range of incomes to those below the median; and because, with a much smaller

225 sample size than Nettle and Bateson (2019), statistical power for additional control variables

226 was more limited.

227 NHANES data

228 To compare the patterns found in the UK data with those from NHANES 2013-4, we

229 repeated the analyses reported by Nettle and Bateson (2019), but with all genders pooled. As

230 per the approach adopted by Nettle \& Bateson (2019), we controlled for age, income,

231 education, ethnicity, and presence of children in the household as well as gender. Again, we

232 first performed MANOVAs on the three sets of variables, followed by separate univariate

233 general linear models on each outcome variable.

234 Results

235 Descriptive statistics

236 Descriptive statistics for the main food consumption variables for the UK sample and the 237 pooled data from the NHANES 2013-14 cycle are shown in Table 1. 
Table 1. Variables extracted from the food recalls for the current study and NHANES pooled data

\begin{tabular}{|c|c|c|c|c|c|}
\hline & Variable name & Definition & Units & $\begin{array}{l}\text { UK data } \\
\text { Mean (sd) }\end{array}$ & $\begin{array}{c}\text { NHANES 2013-4 } \\
\text { Mean (sd) }\end{array}$ \\
\hline Consumption amounts & $\begin{array}{c}\text { Energy intake } \\
\text { Carbohydrate } \\
\text { Protein } \\
\text { Fat } \\
\text { Fibre }\end{array}$ & $\begin{array}{c}\text { Total energy intake per day } \\
\text { Carbohydrate } \\
\text { Protein } \\
\text { Fat } \\
\text { Fibre }\end{array}$ & $\begin{array}{l}\text { kcals } \\
\mathrm{g} \\
\mathrm{g} \\
\mathrm{g} \\
\mathrm{g}\end{array}$ & $\begin{array}{c}1759(680) \\
218.92(95.21) \\
67.22(28.2) \\
69.8(30.93) \\
16.48(8.61)\end{array}$ & $\begin{array}{c}2056(878) \\
247.89(112.52) \\
81.96(39.48) \\
78.5(40.07) \\
16.9(9.54)\end{array}$ \\
\hline Intraday patterns & $\begin{array}{c}\text { First CE } \\
\text { Number of CE } \\
\text { Mean foods per CE } \\
\text { Variability foods per CE } \\
\text { Variability time gap } \\
\text { Variability energy per } \\
\text { CE }\end{array}$ & $\begin{array}{c}\text { Time of first CE } \\
\text { Mean number of CE per day } \\
\text { Mean number of distinct foods per CE } \\
\text { Intraday standard deviation number of } \\
\text { distinct foods per CE } \\
\text { Intraday standard deviation in time gap } \\
\text { between CEs } \\
\text { Intraday standard deviation Kcals per } \\
\text { CE }\end{array}$ & $\begin{array}{l}\text { Hours from } \\
\text { midnight } \\
\text { Number } \\
\text { Number } \\
\text { Number } \\
\text { Minutes } \\
\text { kcals }\end{array}$ & $\begin{array}{c}9.3(1.9) \\
4.07(1.08) \\
3.41(1.02) \\
1.47(0.68) \\
93.38(45.3) \\
334.23(247.19)\end{array}$ & $\begin{array}{c}7.9(2.3) \\
5.47(1.63) \\
9.63(3.3) \\
5.34(1.94) \\
109.42(55.88) \\
407.38(195.52)\end{array}$ \\
\hline Interday variability $^{1}$ & $\begin{array}{l}\text { IDSD energy intake } \\
\text { IDSD first CE } \\
\text { IDSD number of foods } \\
\text { IDSD number of CEs } \\
\text { IDSD mean time gap }\end{array}$ & $\begin{array}{l}\text { Interday standard deviation energy } \\
\text { intake } \\
\text { Interday standard deviation time of } \\
\text { first CE } \\
\text { Interday standard deviation number of } \\
\text { foods } \\
\text { Interday standard deviation number of } \\
\text { CEs } \\
\text { Interday standard deviation mean time } \\
\text { gap between CEs }\end{array}$ & $\begin{array}{l}\text { Kcals } \\
\text { Hours } \\
\text { Number } \\
\text { Number } \\
\text { Minutes }\end{array}$ & $\begin{array}{c}587(614.94) \\
1.42(1.52) \\
0.68(0.4) \\
0.74(0.6) \\
47.78(34.49)\end{array}$ & $\begin{array}{c}736.11(688.83) \\
1.83(2.40) \\
4.62(3.90) \\
1.51(1.33) \\
68.6974 .60)\end{array}$ \\
\hline
\end{tabular}




\section{Main analyses}

243 Results of the main analyses for both the UK and NHANES datasets are summarized in Table 2442

$245 \quad$ UK dataset

246 There was no significant effect of FI overall for the five food consumption variables. Follow

247 up univariate analysis of the individual variables showed that food insecure adults consumed

248 significantly more carbohydrate but less protein relative to their total energy intake than their

249 food secure counterparts. There was no significant difference by FI status in total energy

250 intake or relative fat and fibre consumption. There was a significant overall effect of FI on

251 intraday patterns of eating. Food insecure adults consumed a significantly smaller and less

252 variable number of foods per CE and had larger and more variable time gaps between CEs.

253 However, there was no significant difference in the time of the first meal, the number of

254 meals consumed, or the amount of energy consumed at each meal. There was no significant

255 effect of FI on the interday patterns of eating, either in the MANOVA nor in relation to any

256 of the individual variables.

257 Standardized parameter estimates, plus 95\% confidence intervals, from the univariate

258 analyses are shown in figure 2. The variables are ordered from the largest to the smallest

259 absolute parameter estimate in Nettle and Bateson (2019), rather than the order of their size in 260 the UK dataset. 
Table 2. Parameter estimates for the difference between food-secure and food insecure participants. Food secure is the reference category, the parameter estimates represent the deviation of the food insecure participants from the food secure participants

\begin{tabular}{|c|c|c|c|c|}
\hline & \multicolumn{2}{|l|}{ UK dataset } & \multicolumn{2}{|c|}{ NHANES pooled dataset } \\
\hline & $B(s e)$ & $p$-value & $B(s e)$ & $p$-value \\
\hline Consumption variables & MANOVA F $(5,387)=1.25$ & 0.28 & MANOVA F $(5,4947)=36.18$ & $<0.001$ \\
\hline Energy intake per day & $-49.68(66.04)$ & 0.45 & $18.03(30.17)$ & 0.50 \\
\hline Relative carbohydrate & $8.32(4.13)$ & 0.04 & $5.52(1.36)$ & $<0.001$ \\
\hline Relative protein & $-3.42(1.69)$ & 0.04 & $-3.35(0.95)$ & $<0.001$ \\
\hline Relative fat & $-1.45(1.48)$ & 0.33 & $-1.14(0.79)$ & 0.14 \\
\hline Relative fibre & $-1.16(0.69)$ & 0.09 & $-1.02(0.25)$ & $<0.001$ \\
\hline Intraday pattern variables & MANOVA F $(8,373)=2.50$ & 0.01 & MANOVA $(\mathrm{F} 6,4727)=47.12$ & $<0.001$ \\
\hline First CE & $2.24(11.75)$ & 0.85 & $-0.02(0.08)$ & 0.77 \\
\hline Number of CE & $-0.11(0.11)$ & 0.32 & $-0.13(0.06)$ & $<0.05$ \\
\hline Mean foods per CE & $-0.28(0.10)$ & 0.01 & $-0.41(0.12)$ & $<0.001$ \\
\hline Variability foods per CE & $-0.23(0.07)$ & $<0.001$ & $-0.29(0.07)$ & $<0.001$ \\
\hline Variability time gap & $9.09(4.58)$ & 0.048 & $8.31(2.01)$ & $<0.001$ \\
\hline Variability energy per CE & $-0.92(24.60)$ & 0.97 & $6.56(6.71)$ & 0.32 \\
\hline Interday variability variables & MANOVA F $(5,366)=1.23$ & 0.30 & MANOVA F $(5,4365)=15.48$ & $<0.001$ \\
\hline IDSD energy intake & $26.04(62.14)$ & 0.68 & $45.38(26.08)$ & 0.08 \\
\hline IDSD first CE & $16.87(9.21)$ & 0.07 & $0.11(0.09)$ & 0.24 \\
\hline IDSD number of foods & $-0.04(0.04)$ & 0.37 & $0.18(0.16)$ & 0.27 \\
\hline IDSD number of CEs & $0.04(0.04)$ & 0.35 & $0.05(0.05)$ & 0.32 \\
\hline IDSD mean time gap & $6.70(3.56)$ & 0.06 & $3.76(2.88)$ & 0.19 \\
\hline
\end{tabular}




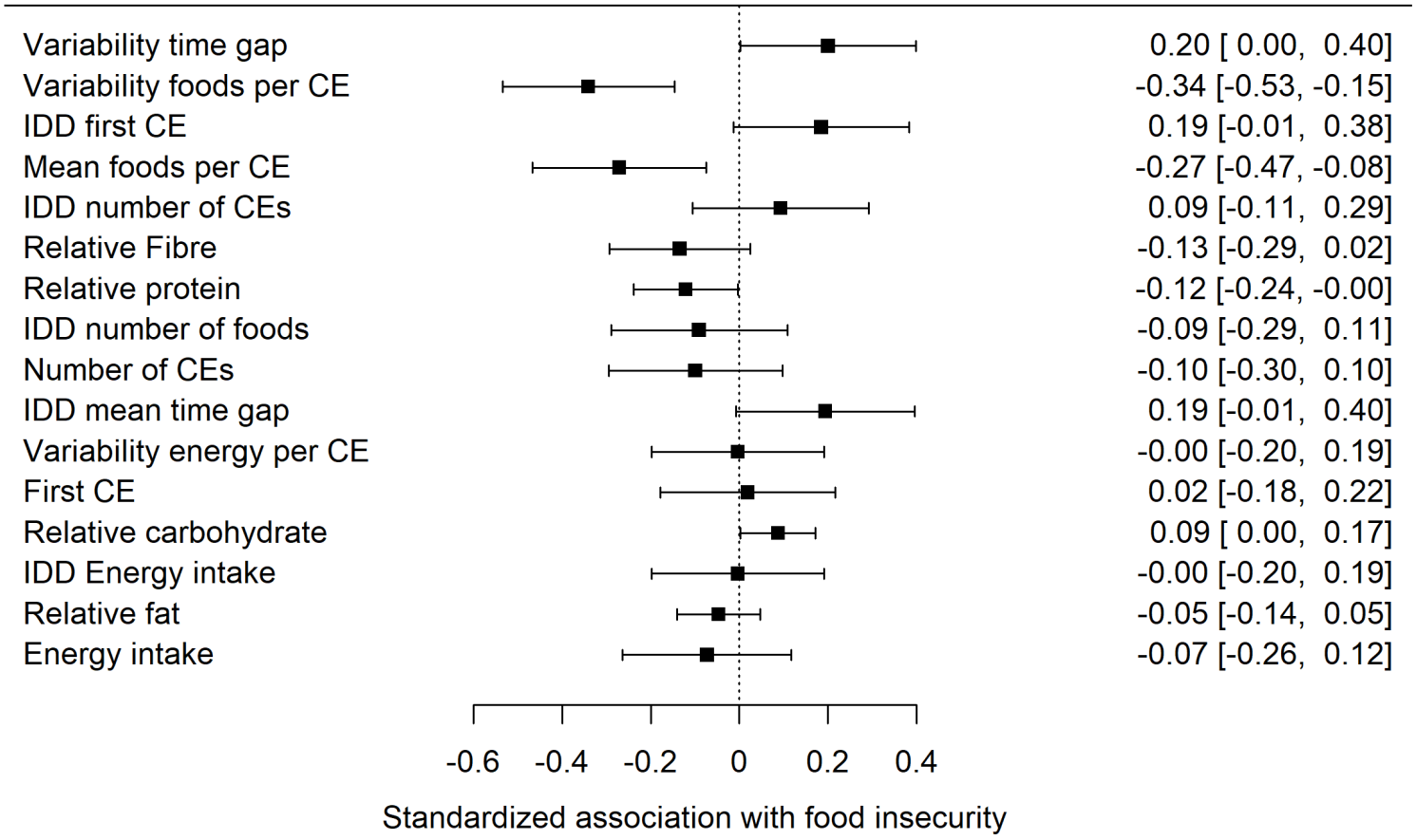

265 Figure 2. Standardized associations (plus 95\% confidence interval) of the sixteen dietary variables with food insecurity status in the UK dataset. The order in which the variables appear is for direct comparability against figure 1 of Nettle and Bateson (2019).

NHANES dataset

270 For the five food consumption variables, there was a significant effect of FI overall. Food insecure adults in the NHANES sample consumed significantly more carbohydrate, but less protein and less fibre relative to energy intake than food secure adults. There was a significant effect of FI overall on intraday patterns of eating. Food insecure adults had fewer

274 CEs each day, ate a smaller and less variable number of foods at each CE and had fewer 275 distinct foods at each CE with more variable time gaps between CEs. There was no significant difference in the time of the first CE, nor in the total amount of energy consumed at each CE. There was a significant effect overall of FI on interday variation in patterns of eating. However, in the follow up analyses, none of the individual variables differed significantly by FI status. 


\section{Comparison of associations with FI in UK and NHANES datasets}

Comparing which associations are significant in the UK and NHANES data is a poor way of assessing the similarity of patterns, since the much smaller sample from the UK means that associations are estimated with much less statistical power. Therefore, to investigate the extent to which being food insecure is associated with the same patterns of eating in our UK sample as in the NHANES sample, we compared the standardized parameter estimates related to FI status for each of the sixteen consumption variables. The pattern of associations was extremely similar for the two samples (correlation of parameter estimates between UK sample and NHANES, $\mathrm{r}=0.86, \mathrm{p}<0.001$; see figure 3 ).

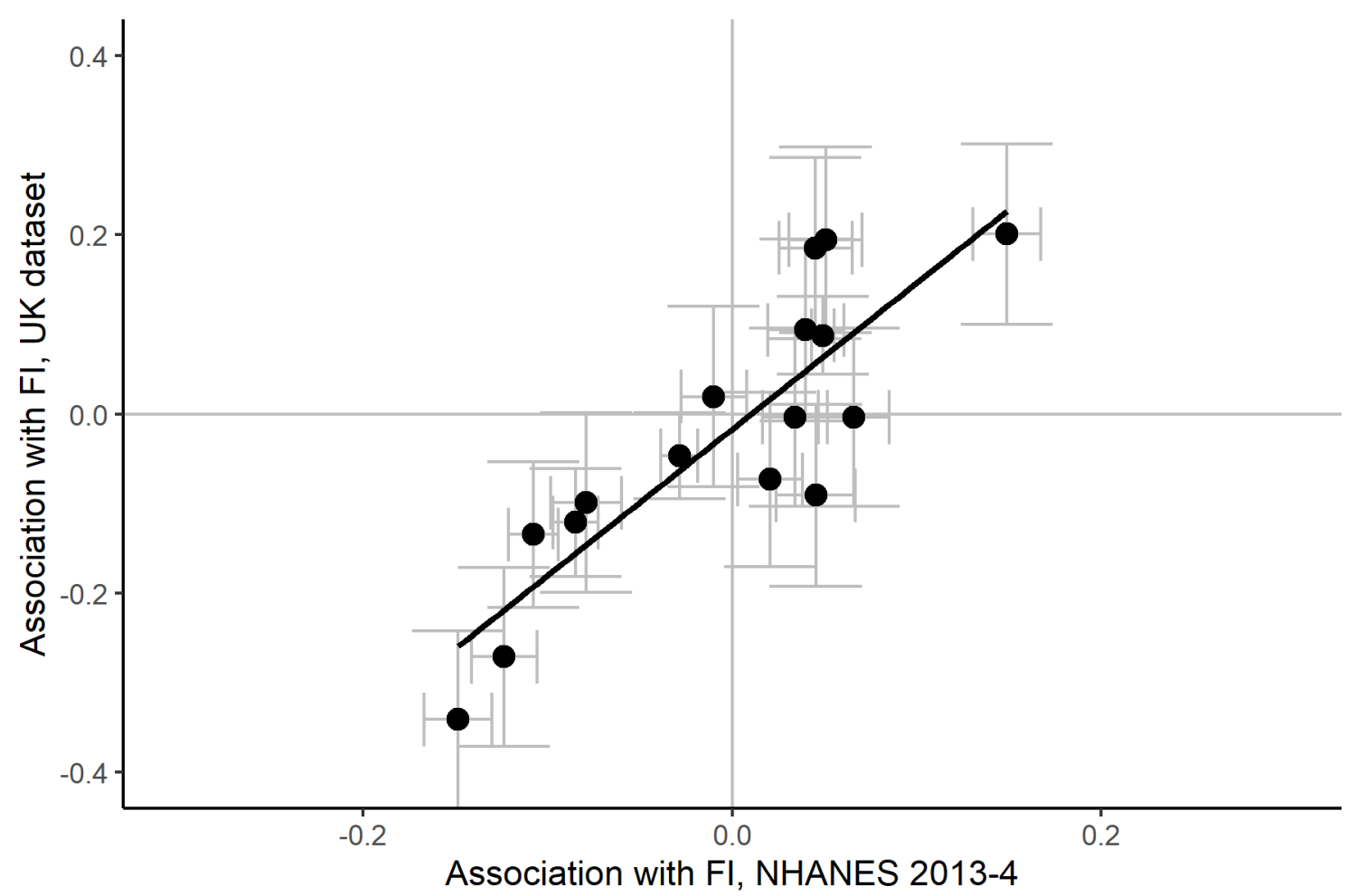

Figure 3. Standardized associations with food insecurity status in the NHANES 2013-4 dataset against those in the UK dataset. Each point represents one variable. Error bars represent one standard error in the corresponding dataset.

\section{Association between FI and BMI}

There was no significant association between BMI and FI status in the UK sample, even including an expected interaction with gender: $\mathrm{B}_{\text {female }}=1.19$, se 1.12, $\mathrm{t}=-1.06, \mathrm{p}=0.29 ; \mathrm{B}_{\mathrm{FI}}=$ 0.10, se $1.13, \mathrm{t}=0.08, \mathrm{p}=0.94 ; \mathrm{B}_{\text {interaction }}=0.19$, se $0.91, p=0.91$ ). Thus, we did not investigate mediation of the FI-BMI association by food consumption variables. 


\section{Discussion}

The aim of the current study was to determine whether, in a sample of UK adults, FI as measured by questionnaire was associated with the same patterns of dietary intake as it was in the larger US NHANES sample studied by Nettle and Bateson (2019). It was, to a quite striking extent. Just as in the NHANES dataset, food insecure individuals differed from food secure individuals in the composition of what they ate, and the temporal patterning of their eating, but not in the total number of calories they ate. In some cases, the UK results differed in significance from the NHANES results, but this may be attributed to the very much smaller sample size: the parameter estimates were in all cases extremely similar between the two datasets. In terms of macronutrient composition, food insecure individuals in the UK dataset ate relatively more carbohydrate and less protein. They tended to eat less fibre as well, though this trend was not significant in the UK dataset. In terms of temporal patterning, notably, they ate fewer distinct foods per meal, and with more variable time gaps between meals. These were two of the key patterns also found by Nettle and Bateson (2019). Thus, despite a different population, several years between the two studies, and several important methodological and contextual differences, the two studies reach convergent conclusions about how the eating behaviour of people exposed to food insecurity differs from that of those who are not.

Our finding of fewer distinct foods at each meal and more relative energy from carbohydrate and less from protein is consistent with prior research that shows that the dietary intake of people who experience FI contains low diversity but high amounts of cheaper carbohydrate based foods and lower amounts of quality protein (Dixon et al., 2001; Hanson \& Connor, 2014; Tingay et al., 2003). Accessibility, cost, value for money, how satiating food is and the amount of food relative to the amount of money available to spend all play an important role in the decisions made by food insecure adults when shopping for food (Burns et al., 2013; Caraher et al., 1998; Dawson et al., 2008; A Drewnowski \& Specter, 2004; Tinkler \& Ritchie, 2016). Recent research in the UK for example shows that low income families cannot afford to meet dietary recommendations for good health (Taylor \& Loopstra, 2016). The alternative therefore for low-income families who have less money to spend on food, is to buy cheap, energy dense but nonetheless highly palatable foods (Bocquier et al., 2015; Burns et al., 2013; Drewnowski \& Specter, 2004; Drewnowski, 2010; Kirkpatrick \& Tarasuk, 2007, 2008; Leung et al., 2014). However, other factors in addition to availability of money may influence food choices. The high fat, sugar and salt content of convenience foods make 
these foods highly palatable and therefore potentially more psychologically rewarding ( Drewnowski \& Specter, 2004; Gearhardt et al., 2011).

Prior research has shown that high carbohydrate/low protein diets and high intakes of ultraprocessed foods are associated with high energy intake (Couteur et al., 2016; Drewnowski \& Specter, 2004; Lawrence \& Baker, 2019; Morrison \& Laeger, 2015; Rico-campà et al., 2016). However, although we found that food insecure adults consumed more carbohydrate and less protein relative to their energy intake, we found no significant difference in total energy intake itself. This accords with most previous studies of FI (Basiotis \& Lino, 2002; Burns et al., 2013; Leung et al., 2014; Zizza et al., 2008), though some have found reduced energy intake associated with FI (Dixon et al., 2001; Kirkpatrick \& Tarasuk, 2008). Observational studies have not found evidence for increased energy intake in association with FI in everyday life (Nettle et al., 2019; experimental studies where participants are given staged access to free food may be a different matter; Stinson et al., 2018). This means that the higher BMI that is robustly associated with FI in women (Nettle et al., 2017) is not apparently driven by increased habitual calorie consumption. Rather, differences in energy expenditure, or different obesogenic potential of foods consumed on different temporal schedules (Alhussain et al., 2016; Farshchi et al., 2004), must be implicated. We found no evidence for higher BMI in food insecure women in the current UK sample, but we note that our study was only modestly powered to detect such an association given the expected effect size (Nettle et al., 2017).

A key finding of Nettle and Bateson (2019) was that FI was associated with more variable time gaps between food consumption. They used this to justify connecting FI as studied in the social sciences and routinely measured by questionnaire with a rich experimental tradition in birds, in which time gaps between periods of food access are made more variable and/or unpredictable (Bateson et al., 2021; Bauer et al., 2011; Bednekoff \& Krebs, 1995; Cuthill et al., 2000; Witter et al., 1995; Witter \& Swaddle, 1997). Those studies show that FI leads to weight gain in birds, often without a concomitant increase in energy intake. Moreover, experimentally increasing variability in time gaps between food in humans causes metabolic changes that would, if sustained over the long term, lead to weight gain (Alhussain et al., 2016; Farshchi et al., 2004). The fact that we found the same association between FI and variable time gaps between food in the UK sample further buttresses connecting these experimental literatures with the study of FI in human populations. 
The UK study had several limitations. First, the sample was small: the small number of participants compared to NHANES is not completely offset by the greater precision that arises from having more than two 24-hour food recalls per participant. Second, we relied on an opportunity sample. Although we restricted screening to low-income participants to draw from a relatively homogenous pool and used matching to remove variability due to age and gender, unmeasured socioeconomic or contextual differences between our food secure and food insecure groups may remain, and generalizability to the wider UK food insecure population is unknown. Third, our data collection took place during the coronavirus pandemic of 2020. This has a number of implications. It meant we had to assess FI with respect to the pre-pandemic period, but the dietary recalls themselves took place during the pandemic-affected period. Respondents were more likely to have been at home than usual, may have had routines disrupted, and many were affected by economic hardship. These uncertainties militated against finding stable associations of dietary intake patterns with (prepandemic) exposure to FI. Given these uncertainties, it is, perhaps, all the more remarkable that we found significant associations between FI status and dietary intake patterns, and in particular that these would be so strikingly similar to those of the earlier study in a different population unaffected by the pandemic. This does suggest that the FI questionnaire proxies some repeatable, systematic, general differences in patterns of dietary intake.

A further limitation is the possibility of biased reporting or under-reporting in dietary recalls. We are not concerned with whether the total energy intake was reported accurately, merely with the difference by FI status. Thus, for under-reporting to affect our conclusions, there would have to be differential under-reporting by FI status. This is certainly possible. Underreporting in nutritional intake studies is often associated with social desirability, low income and high BMI (Maukonen et al., 2018; Orcholski et al., 2015; Scagliusi et al., 2009; Schoch \& Raynor, 2012; Shields et al., 2015). Thus, it could also be associated with FI status. Underreporting has been particularly highlighted in relation to total energy intake. Most of our statistically significant findings concern other variables, such as temporal gaps, and the extent to which these are affected by under-reporting or biased reporting is not known.

\section{Conclusion}

The current study adds to findings in the literature that suggest no difference in total energy intake of food secure and food insecure adults in their everyday diets. However, in line with a very different study in the USA, we found that FI is associated with a suite of changes to dietary intake, consisting of more reliance on carbohydrate at the expense of other 
macronutrient groups, less dietary diversity, and more variable time gaps between eating episodes. In view of rising concern about the prevalence of FI in the UK (Department for Work and Pensions, 2021), and the potential health impacts of FI, these patterns are timely and important to understand.

\section{Data availability}

The data and code required to reproduce all analyses reported in this paper are freely available via the Zenodo repository at: https://doi.org/10.5281/zenodo.4668564

\section{Supplementary materials}

Table S1 Demographic information on participants recruited to phase 1 of the study.

\section{References}

Alhussain, M. H., Macdonald, I. A., \& Taylor, M. A. (2016). Irregular meal-pattern effects on energy expenditure, metabolism, and appetite regulation: A randomized controlled trial in healthy normal-weight women. American Journal of Clinical Nutrition, 104(1), 2132. https://doi.org/10.3945/ajcn.115.125401

Basiotis, P. P., \& Lino, M. (2002). Food Insufficiency and Prevalence of Overweight Among Adult Women. Nutrition Insights, 26, 1-2.

Bateson, M., Andrews, C., Dunn, J., Egger, C., Gray, F., Mchugh, M., \& Nettle, D. (2021). Food insecurity increases energetic efficiency, not food consumption: an exploratory study in European starlings. PeerJ.

Bauer, C. M., Glassman, L. W., Cyr, N. E., \& Romero, L. M. (2011). Effects of predictable and unpredictable food restriction on the stress response in molting and non-molting European starlings (Sturnus vulgaris). Comparative Biochemistry and Physiology - A Molecular and Integrative Physiology, 160(3), 390-399. https://doi.org/10.1016/j.cbpa.2011.07.009

Bednekoff, P. A., \& Krebs, J. R. (1995). Great tit fat reserves: effects of changing and unpredictable feeding day length. Functional Ecology, 9, 457-462. https://doi.org/10.2307/2390009

Bocquier, A., Vieux, F., Lioret, S., Dubuisson, C., Caillavet, F., \& Darmon, N. (2015). Socioeconomic characteristics, living conditions and diet quality are associated with food insecurity in France. Public Health Nutrition, 18(16), 2952-2961. 
https://doi.org/10.1017/S1368980014002912

Bradley, J., Simpson, E., Poliakov, I., Matthews, J. N. S., Olivier, P., Adamson, A. J., \& Foster, E. (2016). Comparison of INTAKE24 (an Online 24-h dietary recall tool) with interviewer-led 24-h recall in 11-24 year-old. Nutrients, 8(6). https://doi.org/10.3390/nu8060358

Burns, C., Cook, K., \& Mavoa, H. (2013). Role of expendable income and price in food choice by low income families. Appetite, 71, 209-217. https://doi.org/10.1016/j.appet.2013.08.018

Caraher, M., Dixon, P., Lang, T., \& Carr-Hill, R. (1998). Access to healthy foods: Part I. Barriers to accessing healthy foods: Differentials by gender, social class, income and mode of transport. Health Education Journal, 57(3), 191-201. https://doi.org/10.1177/001789699805700302

Couteur, D. G. Le, Solon-biet, S., Cogger, V. C., Mitchell, S. J., Senior, A., Cabo, R. De, Raubenheimer, D., \& Simpson, S. (2016). The impact of low-protein high-carbohydrate diets on aging and lifespan. Cellular and Molecular Life Sciences, 73(6), 1237-1252. https://doi.org/10.1007/s00018-015-2120-y

Cuthill, I. C., Maddocks, S. A., Weall, C. V., \& Jones, E. K. M. (2000). Body mass regulation in response to changes in feeding predictability and overnight energy expenditure. Behavioral Ecology, 11, 189-195. https://doi.org/10.1093/beheco/11.2.189

Dawson, J., Marshall, D., Taylor, M., Cummins, S., Sparks, L., \& Anderson, A. S. (2008). Accessing healthy food: availability and price of a healthy food basket in Scotland. Journal of Marketing Management, 24(9-10), 893-913. https://doi.org/10.1362/026725708X381957

Department for Work and Pensions. (2021). Family Resources Survey: background information and methodology.

Dixon, L. B., Winkleby, M. A., \& Radimer, K. L. (2001). Dietary intakes and serum nutrients differ between adults from food-insufficient and food-sufficient families: Third National Health and Nutrition Examination Survey, 1988-1994. Journal of Nutrition, 131(4), 1232-1246. https://doi.org/10.1093/jn/131.4.1232

Dowler, E., \& O'Connor, D. (2012). Rights-based approaches to addressing food poverty and 
food insecurity in Ireland and UK. Social Science and Medicine, 74(1), 44-51. https://doi.org/10.1016/j.socscimed.2011.08.036

Drewnowski, A, \& Specter, S. (2004). Poverty and obesity : the role of energy density and energy costs. American Journal of Clinical Nutrition, 79, 6-16.

Drewnowski, Adam. (2010). The cost of US foods as related to their nutritive value. American Journal of Clinical Nutrition, 92(5), 1181-1188. https://doi.org/10.3945/ajen.2010.29300

Farshchi, H. R., Taylor, M., \& Macdonald, I. A. (2004). Decreased thermic effect of food after an irregular compared with a regular meal pattern in healthy lean women. International Journal of Obesity, 28(5), 653-660. https://doi.org/10.1038/sj.ijo.0802616

Gearhardt, A. N., Davis, C., Kuschner, R., \& Brownell, K. D. (2011). The addiction potential of hyperpalatable foods. Curr Drug Abuse Rev, 4(3), 140-145.

Hanson, K., \& Connor, L. (2014). Food insecurity and dietary quality in US adults and children: a systematic review. American Journal of Clinical Nutrition, 100, 684-692. https://doi.org/10.3945/ajcn.114.084525

Howarth, N. C., Huang, T. T. K., Roberts, S. B., Lin, B. H., \& McCrory, M. A. (2007). Eating patterns and dietary composition in relation to BMI in younger and older adults. International Journal of Obesity, 31(4), 675-684. https://doi.org/10.1038/sj.ijo.0803456

Kendall, A., Olson, C. M., \& Frongillo, E. A. (1996). Relationship of hunger and food insecurity to food availability and consumption. In Journal of the American Dietetic Association (Vol. 96, pp. 1019-1024). https://doi.org/10.1016/S0002-8223(96)00271-4

Kirkpatrick, S. I., \& Tarasuk, V. (2007). Adequacy of food spending is related to housing expenditures among lower-income Canadian households. Public Health Nutrition, 10(12), 1464-1473. https://doi.org/10.1017/S136898000700081X

Kirkpatrick, S. I., \& Tarasuk, V. (2008). Food insecurity is associated with nutrient inadequacies among Canadian adults and adolescents. Journal of Nutrition, 138(3), 604612. https://doi.org/10.1093/jn/138.3.604

Kowaleski-Jones, L., Wen, M., \& Fan, J. X. (2018). Unpacking the paradox: testing for mechanisms in the food insecurity and BMI association. Journal of Hunger and Environmental Nutrition, 0248(May), 1-15. 
https://doi.org/10.1080/19320248.2018.1464997

Labayen, I., Ruiz, J. R., Ortega, F. B., Huybrechts, I., Rodríguez, G., Jiménez-Pavón, D., Roccaldo, R., Nova, E., Widhalm, K., Kafatos, A., Molnar, D., Androutsos, O., \& Moreno, L. A. (2014). High fat diets are associated with higher abdominal adiposity regardless of physical activity in adolescents; the HELENA study. Clinical Nutrition, 33(5), 859-866. https://doi.org/10.1016/j.clnu.2013.10.008

Laraia, B. a. (2012). Food Insecurity and Chronic Disease. Advances in Nutrition, 4, $203-$ 212. https://doi.org/10.3945/an.112.003277.Current

Larson, N. I., \& Story, M. T. (2011). Food insecurity and weight status among U.S. children and families: A review of the literature. American Journal of Preventive Medicine, 40(2), 166-173. https://doi.org/10.1016/j.amepre.2010.10.028

Lawrence, M. A., \& Baker, P. I. (2019). Ultra processed foods and adverse health outcomes. Fresh evidence links popular processed foods with a range of health risks. BMJ Clinical Research, July 2020, 1-3. https://doi.org/10.1136/bmj.12289

Leung, C. W., Epel, E. S., Ritchie, L. D., Crawford, P. B., \& Laraia, B. A. (2014). Food Insecurity Is Inversely Associated with Diet Quality of Lower-Income Adults. Journal of the Academy of Nutrition and Dietetics, 114(12), 1943-1953.e2. https://doi.org/10.1016/j.jand.2014.06.353

Martinez, J. A. (2000). Body-weight regulation: Causes of obesity. Proceedings of the Nutrition Society, 59(3), 337-345. https://doi.org/10.1017/S0029665100000380

Maukonen, M., Männistö, S., \& Tolonen, H. (2018). A comparison of measured versus selfreported anthropometrics for assessing obesity in adults: a literature review. Scandinavian Journal of Public Health, 46(5), 565-579. https://doi.org/10.1177/1403494818761971

Morrison, C. D., \& Laeger, T. (2015). Protein-dependent regulation of feeding and metabolism. Trends in Endocrinology \& Metabolism, 26(5), 256-262. https://doi.org/10.1016/j.tem.2015.02.008

Murtaugh, M. A., Herrick, J. S., Sweeney, C., Baumgartner, K. B., Guiliano, A. R., Byers, T., \& Slattery, M. L. (2007). Diet Composition and Risk of Overweight and Obesity in Women Living in the Southwestern United States\{A figure is presented\}. Journal of the 
American Dietetic Association, 107(8), 1311-1321.

https://doi.org/10.1016/j.jada.2007.05.008

Nelson, L. H., \& Tucker, L. A. (1996). Diet compositin related to body fat in a multivariate study of 203 men. Journal of the American Dietetic Association, 96(8), 771-777.

Nettle, D., Andrews, C., \& Bateson, M. (2017). Food insecurity as a driver of obesity in humans: The insurance hypothesis. Behavioral and Brain Sciences, 40, e105. https://doi.org/10.1017/S0140525X16000947

Nettle, D., \& Bateson, M. (2019). Food-Insecure Women Eat a Less Diverse Diet in a More Temporally Variable Way: Evidence from the US National Health and Nutrition Examination Survey, 2013-4. Journal of Obesity, 2019. https://doi.org/10.1155/2019/7174058

Nettle, D., Joly, M., Broadbent, E., Smith, C., Tittle, E., \& Bateson, M. (2019). Opportunistic food consumption in relation to childhood and adult food insecurity : An exploratory correlational study. Appetite, 132, 222-229. https://doi.org/10.1016/j.appet.2018.07.018

Office for National Statistics. (2020). Average household income, UK: financial year ending 2020 (provisional).

Orcholski, L., Luke, A., Plange-Rhule, J., Bovet, P., Forrester, T. E., Lambert, E. V., Dugas, L. R., Kettmann, E., Durazo-Arvizu, R. A., Cooper, R. S., \& Schoeller, D. A. (2015). Under-reporting of dietary energy intake in five populations of the African diaspora. British Journal of Nutrition, 113(3), 464-472. https://doi.org/10.1017/S000711451400405X

Pan, L., Sherry, B., Njai, R., \& Blanck, H. M. (2012). Food Insecurity is Associated with Obesity among US Adults in 12 states. Journal of Acad Nutritional Science, 112(9), 1403-1409. https://doi.org/10.1016/j.jand.2012.06.011. Food

Peer, E., Brandimarte, L., Samat, S., \& Acquisti, A. (2017). Journal of Experimental Social Psychology Beyond the Turk: Alternative platforms for crowdsourcing behavioral research. Journal of Experimental Social Psychology, 70, 153-163. https://doi.org/10.1016/j.jesp.2017.01.006

R Core Development Team. (2020). R: A Language and Environment for Statistical Computing (4.01). R Foundation for Statistical Computing. 
Rico-campà, A., Martínez-gonzález, M. A., Alvarez-alvarez, I., Mendonça, R. D. D., Fuentearrillaga, C. De, Gómez-donoso, C., \& Bes-rastrollo, M. (2016). Association between consumption of ultra-processed foods and all cause mortality : SUN prospective cohort study. BMJ, 365(1949). https://doi.org/10.1136/bmj.11949

Saneei, P., Esmaillzadeh, A., Keshteli, A. H., Feizi, A., Feinle-Bisset, C., \& Adibi, P. (2016). Patterns of dietary habits in relation to obesity in Iranian adults. European Journal of Nutrition, 55(2), 713-728. https://doi.org/10.1007/s00394-015-0891-4

Sarebanhassanabadi, M., Mirhosseini, S. J., Mirzaei, M., Namayandeh, S. M., Soltani, M. H., \& Salehi-Abargouei, A. (2020). The association between a dietary habits score and the risk of metabolic syndrome: A cohort study. Clinical Nutrition, 39(1), 282-290. https://doi.org/10.1016/j.clnu.2019.02.005

Scagliusi, F. B., Ferriolli, E., Pfrimer, K., Laureano, C., Cunha, C. S. F., Gualano, B., Lourenço, B. H., \& Lancha, A. H. (2009). Characteristics of women who frequently under report their energy intake: A doubly labelled water study. European Journal of Clinical Nutrition, 63(10), 1192-1199. https://doi.org/10.1038/ejen.2009.54

Schoch, A. H., \& Raynor, H. A. (2012). Social desirability, not dietary restraint, is related to accuracy of reported dietary intake of a laboratory meal in females during a 24-hour recall. Eating Behaviors, 13, 78-81. https://doi.org/10.1016/j.eatbeh.2011.11.010

Shields, M., Gorber-Connor, S., \& Tremblay, M. S. (2015). Estimates of obesity based on self-report versus direct measures. Health Reports, 19(2). https://doi.org/10.5848/dos.978-1-909293-44-1_8

Simpson, E., Bradley, J., Poliakov, I., Jackson, D., Olivier, P., Adamson, A. J., \& Foster, E. (2017). Iterative development of an online dietary recall tool: INTAKE24. Nutrients, 9(2), 1-14. https://doi.org/10.3390/nu9020118

St-Onge, M. P., Ard, J., Baskin, M. L., Chiuve, S. E., Johnson, H. M., Kris-Etherton, P., \& Varady, K. (2017). Meal Timing and Frequency: Implications for Cardiovascular Disease Prevention: A Scientific Statement from the American Heart Association. Circulation, 135(9), e96-e121. https://doi.org/10.1161/CIR.0000000000000476

Stinson, E. J., Votruba, S. B., Venti, C., Perez, M., Krakoff, J., \& Gluck, M. E. (2018). Food Insecurity is Associated with Maladaptive Eating Behaviors and Objectively Measured 
577

Taylor, A., \& Loopstra, R. (2016). Too Poor to Eat Food insecurity in the UK. Foodfoundation.Org.Uk, May, 1-12. www.foodfoundation.org.uk

Tingay, R. S., Tan, C. J., Tan, N. C. W., Tang, S., Teoh, P. F., Wong, R., \& Gulliford, M. C. (2003). Food insecurity and low income in an English inner city. Journal of Public Health Medicine, 25(2), 156-159. https://doi.org/10.1093/pubmed/fdg032

Tinkler, J., \& Ritchie, J. (2016). Barriers to Healthy Food. In POSTNOTE Number 522 (Issue 522, pp. 1-7). Houses of Parliament.

Townsend, M. S., Peerson, J., Love, B., Achterberg, C., \& Murphy, S. P. (2001). Food insecurity is positively related to overweight in women. The Journal of Nutrition, 131(6), 1738-1745.

USDA Economic Research Services. (2020). Survey Tools.

Vozoris, N. T., \& Tarasuk, V. S. (2003). Household food insufficiency is associated with poorer health. Journal of Nutrition, 133(1), 120-126. https://doi.org/10.1093/jn/133.1.120

Witter, M., \& Swaddle, J. (1997). Mass regulation in juvenile starlings: Response to change in food availability depends on initial body. Functional Ecology, 11(1), 11-15. https://doi.org/10.1046/j.1365-2435.1997.00041.x

Witter, M., Swaddle, J. P., \& Cuthill, I. C. (1995). Periodic food availability and strategic regulation of body mass in the European Starling, Sturnus vulgaris. Functional Ecology, 9(4), 568-574.

Zizza, C. A., Duffy, P. A., \& Gerrior, S. A. (2008). Food insecurity is not associated with lower energy intakes. Obesity, 16(8), 1908-1913. https://doi.org/10.1038/oby.2008.288 
601 Table S1. Demographic profile of phase 1 screening exercise participants, by gender and food 602 insecurity status.

\begin{tabular}{llllll}
\hline \multirow{2}{*}{ Characteristic } & \multicolumn{2}{c}{ Male } & \multicolumn{1}{c}{ Female } & Other \\
\cline { 2 - 6 } & $\begin{array}{l}\text { Food } \\
\text { secure }\end{array}$ & $\begin{array}{l}\text { Food } \\
\text { insecure }\end{array}$ & $\begin{array}{l}\text { Food } \\
\text { secure }\end{array}$ & $\begin{array}{l}\text { Food } \\
\text { insecure }\end{array}$ & $\begin{array}{l}\text { Food } \\
\text { secure }\end{array}$ \\
\hline $\mathrm{N}$ & 500 & 98 & 764 & 134 & 4 \\
Mean age (SD) & $38(13)$ & $35(11)$ & $38(13)$ & $34(10)$ & $29(3)$ \\
Employed & 339 & 59 & 525 & 82 & 2 \\
$\begin{array}{l}\text { Unemployed/Furloughed// } \\
\text { Retired/Ill health etc. }\end{array}$ & 161 & 39 & 243 & 52 & 2 \\
$\begin{array}{l}\text { Household type } \\
\quad \text { Homeowner }\end{array}$ & 221 & 12 & & & \\
$\quad \begin{array}{llll}\text { Rent } \\
\text { Live with parents }\end{array}$ & 153 & 54 & 225 & 35 & \\
$\begin{array}{l}\text { Number of people living } \\
\text { in the household (SD) }\end{array}$ & $2.6(1.2)$ & $2.8(1.3)$ & $2.8(1.1)$ & $3.1(1.4)$ & $3.2(1.9)$ \\
\hline
\end{tabular}

